\title{
Efektivitas Sistem Informasi Akuntansi, Kesesuaian Tugas, dan Pemanfaatan Teknologi Informasi pada Kinerja Pegawai
}

\author{
Dian Savitri Udayana ${ }^{1}$ \\ Gede Juliarsa ${ }^{2}$ \\ 1,2Fakultas Ekonomi dan Bisnis Universitas Udayana, Indonesia \\ ${ }^{*}$ Correspondences : sdian175@gmail.com
}

\begin{abstract}
ABSTRAK
Kinerja merupakan tingkat keberhasilan yang dicapai oleh seseorang dalam melaksanakan tugas yang dibandingkan dengan standar kerja atau kriteria yang telah ditentukan dan disepakati sebelumnya. Tujuan penelitian untuk memberikan bukti empiris mengenai pengaruh efektivitas penerapan sistem informasi akuntansi, kesesuaian tugas dengan teknologi informasi, dan pemanfaatan teknologi informasi pada kinerja pegawai koperasi. Penelitian ini dilakukan pada Koperasi Tani Usaha Mandiri Desa Gadungan, Tabanan. Jumlah sampel yang digunakan sebanyak 40 sampel, dengan metode yang digunakan yaitu teknik sampling jenuh. Pengumpulan data dilakukan dengan kuesioner. Teknik analisis yang digunakan adalah teknik analisis regresi linier berganda. Hasil penelitian ditemukan bahwa efektivitas penerapan sistem informasi akuntansi, kesesuaian tugas, dan pemanfaatan teknologi informasi berpengaruh positif signifikan pada kinerja pegawai koperasi Tani Usaha Mandiri Desa Gadungan, Tabanan.
\end{abstract}

Kata Kunci: Efektivitas Penerapan Sistem Informasi Akuntansi; Kesesuaian Tugas; Pemanfaatan Teknologi Informasi; Kinerja Pegawai.

Effectiveness of Accounting Information Systems, Suitability of Tasks, and Utilization of Information Technology on Employee Performance

\section{ABSTRACT}

Performance is the level of success achieved by a person in carrying out tasks compared to work standards or criteria that have been determined and agreed in advance. The purpose of this research is to provide empirical evidence regarding the effect of the effectiveness of the application of accounting information systems, the suitability of tasks with information technology, and the use of information technology on the performance of cooperative employees. This research was conducted at the Independent Farmers' Cooperative, Gadungan Village, Tabanan. The number of samples used as many as 40 samples, with the method used is the saturated sampling technique. Data was collected by means of a questionnaire. The analysis technique used is multiple linear regression analysis technique. The results of the study found that the effectiveness of the application of accounting information systems, task suitability, and the use of information technology had a significant positive effect on the performance of the employees of the Tani Usaha Mandiri cooperative in Gadungan Village, Tabanan.

Keywords: The Effect of The Efectiveness Accounting Information System Implementation; Duty Suitability; Utilization of Information Technolog; The Employee Performance.

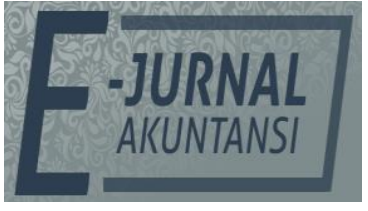

e-ISSN 2302-8556

Vol. 32 No. 1

Denpasar, Januari 2021

Hal. 255-264

DOI:

10.24843/EJA.2022.v32.i01.p19

PENGUTIPAN:

Udayana, D. S. \& Juliarsa, G.

(2022). Efektivitas Sistem

Informasi Akuntansi,

Kesesuaian Tugas, dan

Pemanfaatan Teknologi

Informasi pada Kinerja

Pegawai. E-Jurnal Akuntansi,

32(1), 255-264

RIWAYAT ARTIKEL:

Artikel Masuk:

13 Desember 2021

Artikel Diterima:

5 Januari 2022

Artikel dapat diakses : https://ojs.unud.ac.id/index.php/Akuntansi/index 


\section{PENDAHULUAN}

Perkembangan dunia teknologi informasi yang semakin pesat membuat perubahan terhadap cara kerja setiap individu maupun organisasi yang awalnya manual menjadi lebih canggih. Keunggulan dari teknologi banyak dijadikan sebagai suatu strategi dan peluang dalam perkembangan dunia bisnis terutama dalam hal penerapan sistem informasi. Menurut (Baig \& Gururajan, 2011) teknologi informasi merupakan salah satu sarana untuk meningkatkan kinerja perusahaan dan bisnis. Kebutuhan akan informasi yang cepat, andal dan akurat dalam kondisi lingkungan yang penuh dengan ketidakpastian mutlak diperlukan (Sabherwal \& King, 1992). Kinerja individu dan organisasi berpotensi diperbaiki melalui teknologi informasi khususnya teknologi komputer.

Akuntansi sebagai bisnis, sistem bahasa dan informasi harus menyesuaikan diri dengan teknologi baru yang akan disampaikan kepada pengguna laporan keuangan (Sarokolaei et al., 2012). Kualitas informasi yang baik merupakan salah satu keunggulan yang dimiliki oleh perusahaan (Soudani, 2012). Manfaat yang diperoleh dari penggunaan teknologi informasi membuat teknologi semakin diterima sebagai sesuatu yang wajib dimanfaatkan dan menjadi kebutuhan di dalam organisasi. Permasalahan yang sering muncul yaitu ketika karyawan tidak memanfaatkan teknologi yang disediakan secara maksimal dalam membantu penyelesaian tugas, sehingga teknologi kurang memberikan manfaat yang tepat. Penerapan sistem informasi pada koperasi akan memengaruhi kinerja individu dalam koperasi baik secara langsung maupun tidak langsung. Penerapan sistem informasi pada koperasi dapat memberikan dampak positif maupun dampak negatif terhadap kinerja individu.

Kinerja merupakan tingkat keberhasilan yang dicapai oleh seseorang dalam melaksanakan tugas yang dibandingkan dengan standar kerja atau kriteria yang telah ditentukan dan disepakati sebelumnya (Yualina \& Suhana, 2012). Pencapaian kinerja juga berkaitan dengan kesesuaian antara sistem informasi yang diterapkan dengan tugas, kebutuhan dan kemampuan individu dalam organisasi tersebut. Tugas, kebutuhan dan kemampuan individu hendaknya dipertimbangkan dalam menerapkan suatu sistem informasi dalam organisasi. Goodhue \& Thompson (1995) menemukan kecocokan tugas dan teknologi akan mengarahkan individu untuk mencapai kinerja yang lebih baik. Kinerja individu berkaitan dengan pencapaian serangkaian tugas-tugas individu dengan dukungan teknologi informasi yang ada.

Sistem informasi akuntansi adalah komponen dan elemen dari suatu organisasi yang menyediakan informasi bagi pengguna dengan pengolahan peristiwa keuangan (Zare, 2012). Informasi akuntansi yang berkualitas menjadi salah satu hal penting bagi perusahaan sebab informasi tersebut menjadi dasar dalam pengambilan keputusan (Nwokeji, 2012). Sistem informasi akuntansi menjadi salah satu sarana penting bagi perusahaan dalam meningkatkan kinerjanya (Al-eqab et al., 2013).Sistem informasi akuntansi menjadi bagian penting dalam upaya peningkatan efisiensi dan peningkatan kualitas informasi keuangan (Alsarayreh et al., 2011).

Sistem informasi akuntansi merupakan sistem yang terkait dengan teknologi di bidang akuntansi yang dapat membantu dalam pengelolaan dan pengendalian data-data serta informasi-informasi keuangan (Urquia, 2011). 
Fungsi dari sistem informasi akuntansi yaitu untuk mengumpulkan dan menyimpan aktivitas yang dilaksanakan di suatu perusahaan, mengubah data menjadi informasi yang berguna bagi pihak manajemen, dan menyediakan pengendalian yang memadai sebagai pendukung pengambilan keputusan, pendukung kegiatan operasional, perencanaan, pengendalian, dan perbaikan dimasa yang akan datang. Efektivitas sistem informasi akuntansi merupakan suatu ukuran yang memberikan gambaran sejauh mana target dapat dicapai dari suatu kumpulan sumber daya yang diatur untuk mengumpulkan, memproses, dan menyimpan data elektronik, kemudian mengubahnya menjadi sebuah informasi yang berguna serta menyediakan laporan formal yang dibutuhkan dengan baik secara kualitas maupun waktu.

Koperasi Tani Usaha Mandiri adalah koperasi yang berlokasi di Desa Gadungan, Kecamatan Selemadeg Timur, Kabupaten Tabanan dan berdiri sejak tahun 2001. Koperasi Tani Usaha Mandiri memiliki status badan hukum sebagai koperasi serba usaha dengan Nomor 31/BH/DISKOP/VII/2007. Koperasi Tani Usaha Mandiri merupakan koperasi serba usaha dengan sektor usaha simpan pinjam dan usaha perdagangan/ toko yang sudah berkembang. Bisnis yang dijalankan antara lain: sembako, alat tulis kantor serta sarana produksi pertanian dan peternakan. Koperasi Tani Usaha Mandiri sudah memanfaatkan teknologi informasi berupa aplikasi dan website serta menerapkan sistem informasi akuntansi berbasis komputer dan internet dalam kegiatan operasionalnya. Koperasi Tani Usaha Mandiri dalam perkembangannya melakukan terobosan baru yaitu penggunaan platform atau aplikasi teknologi informasi bernama "SAKTI.Online". SAKTI kepanjangan dari Sistem Akuntansi Koperasi Berbasis Teknologi Internet. Aplikasi digital SAKTI.Online terdiri dari: SAKTI.Mobile, SAKTI.Retail, SAKTI.Link, dan LACI. Adapun skema kerangka konseptual ini digambarkan sebagai berikut.

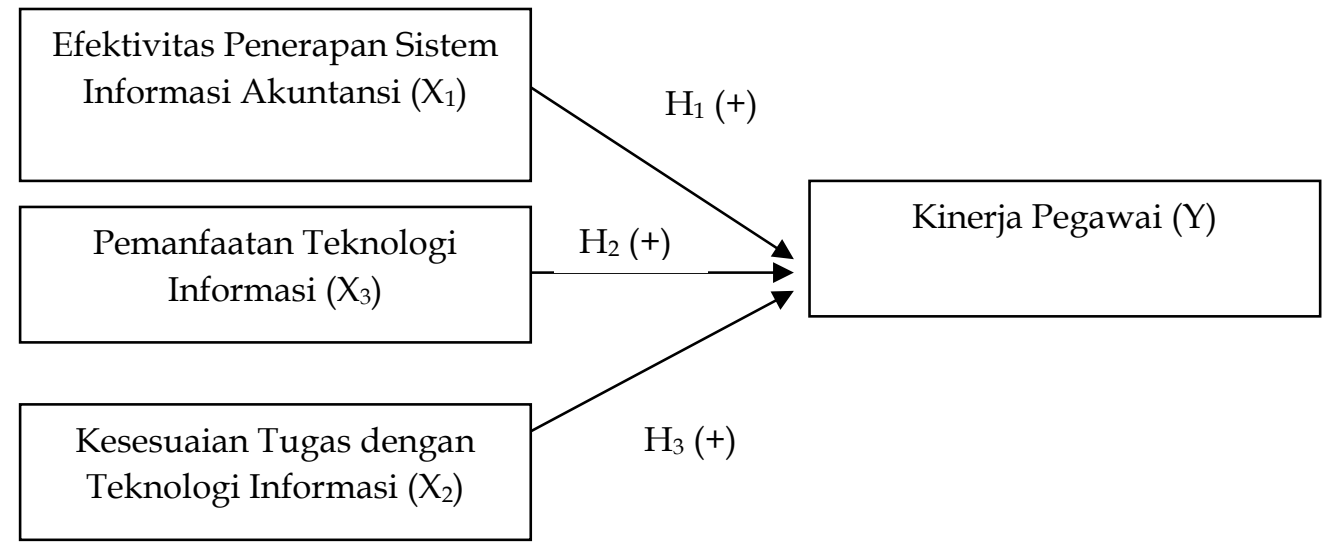

Sumber: Data Penelitian, 2021

Gambar 1. Kerangka Konseptual

Davis (1989) mengembangkan TAM untuk meneliti faktor-faktor determinan dari penggunaan sistem informasi oleh pengguna. TAM percaya bahwa penggunaan sistem informasi dapat meningkatkan kinerja seseorang atau organisasi, serta mempermudah pemakainya dalam menyelesaikan pekerjaan. Jogiyanto (2007:200) Technology-to-Performance Chain (TPC) adalah suatu model 
yang digunakan dalam memahami sikap pemakai sebagai prediktor dari pemakai dan kesesuaian tugas dengan teknologi sebagai prediktor kinerja individu.

Pengukuran kinerja karyawan dilihat dari dampak sistem terhadap efektivitas penyelesaian tugas, membantu meningkatkan kinerja dan menjadikan pemakainya lebih produktif (Melasari, 2017). Dalam hal ini, apabila koperasi menerapkan sistem informasi akuntansi dengan baik maka kinerja pegawai koperasi tersebut lebih baik dibandingkan dengan koperasi yang tidak menerapkan sistem infromasi akuntansi. Hasil penelitian yang dilakukan oleh Hati (2017) penerapan sistem informasi akuntansi memberikan pengaruh yang positif dan signifikan terhadap kinerja pengurus koperasi. Penelitian Jayantara dan Jayantara \& Dharmadiaksa (2016) yang menyatakan efektivitas SIA berpengaruh positif pada kinerja individual. (Awesejo et al., 2013),menemukan pengaruh positif efektivitas penggunaan sistem informasi akuntansi terhadap kinerja.

$\mathrm{H}_{1}$ : Efektivitas Penerapan Sistem Informasi Akuntansi berpengaruh positif pada kinerja pegawai koperasi.

Kesesuaian tugas berhubungan dengan kemampuan individual menggunakan teknologi informasi untuk meningkatkan kinerja individual dalam melaksanakan tugas. Adanya kecocokan antara tugas yang sedang dikerjakan dengan teknologi yang diterapkan akan tercapai kinerja individu yang lebih baik (Goodhue \& Thompson, 1995). Teori Technology to Performance Chain (TPC) menjelaskan agar suatu teknologi informasi memberikan dampak positif terhadap kinerja individu, maka teknologi tersebut harus dimanfaatkan dan sesuai dengan pekerjaan yang dilakukan (Dewi \& Dharmadiaksa, 2017). Hasil penelitian yang dilakukan oleh (Hati, 2017) kesesuaian tugas dengan teknologi informasi berpengaruh positif signifikan terhadap kinerja pengurus koperasi. Penelitian lain yang dilakukan oleh Sridarmaningr \& Widhiyani (2018) menyatakan bahwa adanya pengaruh positif antara variabel kesesuaian tugas dengan teknologi informasi dengan variabel kinerja.

$\mathrm{H}_{2}$ : Kesesuaian tugas dengan teknologi informasi berpengaruh positif pada kinerja pegawai koperasi.

Teknologi informasi adalah sarana untuk mengurangi sebuah masalah bagi organisasi karena tidak efisien dan efektifnya suatu pekerjaan. Pemanfaatan teknologi informasi merupakan tingkat penerapan penggunaan teknologi informasi yang akan memengaruhi kinerja individual, dalam hal ini teknologi seperti komputer sangat berpotensi dalam menunjang kinerja untuk mengambil sebuah keputusan dalam perusahaan. Faktor-faktor yang mempengaruhi pemanfaatan teknologi informasi sangat penting untuk diperhatikan agar mampu menghasilkan keputusan yang lebih efektif dan informative (Chintya M et al., 1997). Hasil penilitian yang dilakukan oleh Dewi \& Dharmadiaksa (2017) adanya pengaruh positif pemanfaatan teknologi informasi pada kinerja individu. Pengaruh yang positif ini berarti terdapat hubungan yang searah antara pemanfaatan teknologi informasi dengan kinerja individu. Semakin tinggi tingkat pemanfaatan teknologi informasi, maka semakin tinggi kinerja individu. Penelitian lain yang dilakukan oleh (Dewantari \& Putra, 2019) juga menyatakan bahwa pemanfaatan teknologi informasi berpengaruh positif terhadap kinerja karyawan. 
$\mathrm{H}_{3}$ : Pemanfaatan teknologi informasi berpengaruh positif pada kinerja pegawai koperasi.

\section{METODE PENELITIAN}

Penelitian ini dilakukan di Koperasi Tani Usaha Mandiri Jl. Pahlawan No.1, Desa Gadungan, Kecamatan Selemadeg Timur, Kabupaten Tabanan. Objek penelitian ini mengenai pengaruh efektivitas penerapan sistem informasi akuntansi, kesesuaian tugas, dan pemanfaatan teknologi informasi terhadap kinerja pegawai pada Koperasi Tani Usaha Mandiri. Sumber data yang digunakan data primer yang berupa jawaban kuesioner yaitu seluruh pegawai (manajemen) Koperasi Tani Usaha Mandiri dan data sekunder berupa referensi pada buku dan jurnal. Populasi yang digunakan dalam penelitian ini adalah seluruh pegawai (manajemen) pada Koperasi Tani Usaha Mandiri Desa Gadungan, Tabanan yang terdiri dari general manajer, manajer, pengendali internal, dan pegawai. Sampel yang digunakan dalam penelitian ini sama dengan jumlah populasi. Metode penentuan sampel penelitian ini adalah teknik sampling jenuh. Sehingga jumlah sampel yang digunakan adalah 40 sampel. Variabel bebas dalam penelitian ini adalah efektivitas penerapan sistem informasi akuntansi, kesesuaian tugas dengan teknologi informasi, dan pemanfaatan teknologi informasi, sedangkan variabel terikat dalam penelitian ini adalah kinerja pegawai koperasi. Metode pengumpulan data yang digunakan dalam penelitian ini adalah kuesioner.

Variabel efektivitas penerapan sistem informasi akuntansi menurut DeLone \& McLean (1992) diukur dengan beberapa indikator yaitu system quality, information quality, service quality, information use, user satisfaction dan net benefit. Variabel kesesuaian tugas dengan teknologi informasi diukur dengan beberapa indikator yang diadopsi dari penelitian Astuti \& Dharmadiaksa (2014) diantaranya keakuratan, aksesibilitas, asistensi, tingkat rincian yang tepat, dan kemudahan menggunakan perangkat keras dan lunak. Pemanfaatan teknologi informasi menurut Rahmawati (2008) terdapat enam faktor yang mempengaruhi yaitu faktor sosial, affect, kompleksitas, kesesuaian tugas, konsekuensi jangka panjang, dan kondisi yang memfasilitasi. Menurut Sedarmayanti (2009:51) kinerja karyawan terdiri dari lima aspek yaitu quality of work, promptness, initiative, capability, dan communication. Teknik analisis yang digunakan dalam penelitian ini adalah teknik analisis regresi linier berganda. Persamaan struktural regresi linier berganda dapat dinyatakan sebagai berikut.

$$
Y=\alpha+\beta 1 X 1+\beta 2 X 2+\beta 3 X 3+\varepsilon .
$$

\section{Keterangan:}

$\begin{array}{ll}\mathrm{Y} & =\text { Kinerja Pegawai } \\ \mathrm{a} & =\text { Konstanta } \\ \mathrm{X}_{1} & =\text { Efektivitas penerapan sistem informasi akuntansi } \\ \mathrm{X}_{2} & =\text { Kesesuaian tugas } \\ \mathrm{X}_{3} & =\text { Pemanfaatan teknologi informasi } \\ \beta_{1} & =\text { Koefisien regresi efektivitas penerapan sistem informasi akuntansi } \\ \beta_{2} & =\text { Koefisien regresi kesesuaian tugas } \\ \beta_{3} & =\text { Koefisien regresi pemanfaatan teknologi informasi } \\ \mathcal{E} & =\text { Komponen error }\end{array}$




\section{HASIL DAN PEMBAHASAN}

Statistik deskriptif memberikan informasi mengenai karakteristik variabelvariabel yang mencakup penjelasan tentang nilai rata-rata (mean), standar deviasi, varian, nilai minimum, dan nilai maksimum.

Tabel 1. Deskriptif Statistik

\begin{tabular}{|c|c|c|c|c|c|}
\hline Variabel & $\mathrm{N}$ & Min & $\operatorname{Max}$ & Mean & Std. Deviation \\
\hline $\begin{array}{l}\text { Efektivitas Penerapan Sistem } \\
\text { Informasi Akuntansi }\left(\mathrm{X}_{1}\right)\end{array}$ & 40 & 36 & 60 & 55,53 & 5,472 \\
\hline $\begin{array}{l}\text { Kesesuaian Tugas Dengan } \\
\text { Teknologi Informasi }\left(X_{2}\right)\end{array}$ & 40 & 20 & 25 & 23,70 & 1,698 \\
\hline $\begin{array}{l}\text { Pemanfaatan Teknologi } \\
\text { Informasi }\left(X_{3}\right)\end{array}$ & 40 & 23 & 30 & 27,73 & 2,470 \\
\hline Kinerja Pegawai $(Y)$ & 40 & 18 & 25 & 22,83 & 2,263 \\
\hline
\end{tabular}

Sumber: Data Penelitian, 2021

Variabel efektivitas penerapan sistem informasi akuntansi memiliki nilai minimum sebesar 36 , nilai maksimum sebesar 60 , dan nilai rata-rata sebesar 55,53 dengan standar deviasi sebesar 5,472. Variabel kesesuaian tugas dengan teknologi informasi memiliki nilai minimum sebesar 20, nilai maksimum sebesar 25, dan nilai rata-rata sebesar 23,70 dengan standar deviasi sebesar 1,698. Variabel pemanfaatan teknologi informasi memiliki nilai minimum sebesar 23, nilai maksimum sebesar 30, dan nilai rata-rata sebesar 27,73 dengan standar deviasi sebesar 2,470. Variabel kinerja pegawai memiliki nilai minimum sebesar 18, nilai maksimum sebesar 25, dan nilai rata-rata sebesar 22,83 dengan standar deviasi sebesar 2,263. Uji normalitas dipergunakan untuk menguji apakah model regresi mempunyai variabel bebas dan variabel terikat berdistribusi normal.

Tabel 2. Uji Normalitas (One-Sample Kolmogorov-Smirnov)

\begin{tabular}{lc}
\hline One-Sample Kolmogorov-Smirnov Test & \\
\hline$N$ & 40 \\
Test Statistic & 0,117 \\
Asymp. Sig. (2-tailed) & 0,178 \\
\hline
\end{tabular}

Sumber: Data Penelitian, 2021

Berdasarkan hasil Tabel 2, didapatkan bahwa nilai Asymp. Sig. (2-tailed) Kolmogorov-Smirnov adalah sebesar 0,178 Asymp. Sig. (2-tailed) Nilai KolmogorovSmirnov tersebut lebih besar dibandingkan dengan nilai alpha sebesar 0,05 sehingga dapat disimpulkan bahwa model memenuhi asumsi normalitas. Uji multikolinearitas dilakukan untuk melihat apakah terdapat korelasi yang sempurna antar variabel bebas yang digunakan pada penelitian ini.

Tabel 3. Uji Multikolinieritas (Tolerance dan Variance Inflation Factor)

\begin{tabular}{lcc}
\hline Variabel & $\begin{array}{c}\text { Collinearity Statistics } \\
\text { Tolerance }\end{array}$ & VIF \\
\hline $\begin{array}{l}\text { Efektivitas Penerapan Sistem } \\
\text { Informasi Akuntansi }\left(\mathrm{X}_{1}\right)\end{array}$ & 0,775 & 1,291 \\
$\begin{array}{l}\text { Kesesuaian Tugas Dengan Teknologi } \\
\text { Informasi }\left(\mathrm{X}_{2}\right)\end{array}$ & 0,646 & 1,548 \\
$\begin{array}{l}\text { Pemanfaatan Teknologi Informasi } \\
\left(\mathrm{X}_{3}\right)\end{array}$ & 0,623 & 1,605 \\
\hline
\end{tabular}

Sumber: Data Penelitian, 2021 
Berdasarkan Tabel 3, tersebut ditunjukkan bahwa tidak terdapat variabel bebas yang memiliki nilai tolerance kurang dari 0,10 dan juga tidak ada variabel bebas yang memiliki nilai VIF lebih dari 10. Maka dari pada itu model regresi bebas dari gejala multikoleniaritas. Uji heteroskedastisitas diakukan melalui metode glesjer untuk mendapatkan nilai residualnya, kemudian nilai residual tersebut diabsolutkan dan dilakukan regresi dengan semua variabel independen.

Tabel 4. Uji Heteroskedastisitas (Uji Glesjer)

\begin{tabular}{lcc}
\hline Variabel & $\mathrm{T}$ & Sig. \\
\hline Efektivitas Penerapan Sistem Informasi & $-1,650$ & 0,108 \\
Akuntansi $\left(\mathrm{X}_{1}\right)$ & $-1,145$ & 0,260 \\
Kesesuaian Tugas Dengan Teknologi & 0,172 & 0,865 \\
Informasi $\left(\mathrm{X}_{2}\right)$ & & \\
Pemanfaatan Teknologi Informasi $\left(\mathrm{X}_{3}\right)$ & &
\end{tabular}

Sumber: Data Penelitian, 2021

Berdasarkan Tabel 4. tersebut, ditunjukkan bahwa masing-masing variabel yaitu Efektivitas Penerapan Sistem Informasi Akuntansi (0,108), Kesesuaian Tugas Dengan Teknologi Informasi $(0,260)$, Pemanfaatan Teknologi Informasi $(0,865)$, memiliki nilai signifikansi lebih besar dari 5\% $(0,05)$, maka dari itu penelitian ini bebas dari gejala heteroskedastisitas. Analisis regresi linear berganda digunakan untuk mendapat koefisien regresi yang akan menentukan apakah hipotesis yang dibuat akan diterima atau ditolak. Adapun hasil analisis regresi dengan program SPSS versi 25.0 for Windows dapat dilihat pada Tabel 5, berikut.

Tabel 5. Rangkuman Hasil Analisis Regresi Linear Berganda

\begin{tabular}{|c|c|c|c|c|c|}
\hline \multirow{2}{*}{ Variabel } & \multicolumn{2}{|c|}{ Koefisien Regresi } & \multirow{2}{*}{$\mathrm{t}$} & \multirow{2}{*}{ Sig } & \multirow{2}{*}{$\begin{array}{l}\text { Hasil Uji } \\
\text { Hipotesis }\end{array}$} \\
\hline & $\mathrm{B}$ & Std. Error & & & \\
\hline \multicolumn{6}{|l|}{ Efektivitas Penerapan } \\
\hline $\begin{array}{l}\text { Sistem Informasi Akuntansi } \\
\left(X_{1}\right)\end{array}$ & 0,334 & 0,146 & 2,286 & 0,028 & $\mathrm{H}_{\mathrm{a}}$ Diterima \\
\hline $\begin{array}{l}\text { Kesesuaian Tugas Dengan } \\
\text { Teknologi Informasi }\left(X_{2}\right)\end{array}$ & 0,319 & 0,110 & 2,905 & 0,006 & $\mathrm{H}_{\mathrm{a}}$ Diterima \\
\hline $\begin{array}{l}\text { Pemanfaatan Teknologi } \\
\text { Informasi }\left(X_{3}\right)\end{array}$ & 0,167 & 0,051 & 3,302 & 0,002 & $\mathrm{H}_{\mathrm{a}}$ Diterima \\
\hline (Constant) & \multicolumn{5}{|c|}{ : $-3,199$} \\
\hline F Statistik & \multicolumn{5}{|c|}{$: 23,868$} \\
\hline $\operatorname{Sig} F$ & \multicolumn{5}{|c|}{$: 0,000$} \\
\hline Adjusted $R^{2}$ & \multicolumn{5}{|c|}{$: 0,638$} \\
\hline
\end{tabular}

Sumber: Data Penelitian, 2021

Berdasarkan Tabel 5, dapat disusun persamaan prediksian regresi linier berganda sebagai berikut.

$$
Y=-3,199+0,334 X_{1}+0,319 X_{2}+0,167 X_{3}
$$

Pada hasil uji hipotesis dengan kriteria $\mathrm{H}_{1}$ diterima jika $\beta_{1}>0$ dan signifikansi $\beta_{1}<0,05$, diketahui bahwa variabel efektivitas penerapan sistem informasi akuntansi diperoleh hasil nilai koefisien regresi $0,334>0$ dan nilai signifikansi 0,028 $<0,05$ mengindikasikan bahwa $\mathrm{H}_{1}$ diterima karena efektivitas penerapan sistem informasi akuntansi berpengaruh positif terhadap kinerja pegawai pada Koperasi Tani Usaha Mandiri Desa Gadungan, Tabanan. Hasil uji hipotesis dengan kriteria $\mathrm{H}_{2}$ diterima jika $\beta_{1}>0$ dan signifikansi $\beta_{1}<0,05$, 
diketahui bahwa variabel kesesuaian tugas dengan teknologi informasi diperoleh hasil nilai koefisien regresi $0,319>0$ dan nilai signifikansi 0,006 $<$ 0,05 mengindikasikan bahwa $\mathrm{H}_{2}$ diterima karena kesesuaian tugas dengan teknologi informasi berpengaruh positif terhadap kinerja pegawai pada Koperasi Tani Usaha Mandiri Desa Gadungan, Tabanan. Hasil uji hipotesis dengan kriteria $\mathrm{H}_{3}$ diterima jika $\beta_{1}>0$ dan signifikansi $\beta_{1}<0,05$, diketahui bahwa variabel pemanfaatan teknologi informasi diperoleh hasil nilai koefisien regresi 0,167 >0 dan nilai signifikansi 0,002 $<0,05$ mengindikasikan bahwa $\mathrm{H}_{3}$ diterima karena pemanfaatan teknologi informasi berpengaruh positif terhadap kinerja pegawai pada Koperasi Tani Usaha Mandiri Desa Gadungan, Tabanan.

\section{SIMPULAN}

Berdasarkan hasil penelitian yang telah diuraikan, maka dapat disimpulkan efektivitas penerapan sistem informasi akuntansi, kesesuaian tugas, dan pemanfaatan teknologi informasi berpengaruh positif signifikan terhadap kinerja pegawai pada Koperasi Tani Usaha Mandiri Desa Gadungan, Tabanan. Diharapkan aplikasi ataupun sistem dan teknologi informasi yang digunakan koperasi bisa ditingkatkan dan terus dievaluasi agar sesuai dengan perkembangan teknologi sehingga dapat bersaing dalam memberikan pelayanan yang cepat terhadap nasabah, dapat meningkatkan produktivitas koperasi serta dapat menunjang pekerjaan pegawai dan meminimalisir kesalahan yang dilakukan pegawai ataupun sistem sehingga kinerja pegawai dan koperasi terus meningkat. Bagi peneliti selanjutnya diharapkan tidak hanya berpaku pada faktor-faktor dalam penelitian ini yaitu Efektivitas Penerapan Sistem Informasi Akuntansi, Kesesuaian Tugas Dengan Teknologi Informasi, dan Pemanfaatan Teknologi Informasi, namun dapat menambah faktor-faktor lain yang mungkin mempengaruhi Kinerja Pegawai.

\section{REFERENSI}

Al-eqab, Mahmod, \& Dalia Adel. (2013). International Jurnal of Business and Social Science. The Impact of IT Sophosticutions on the Perceived Useful of Accounting Information Characteristics among Jordanian Listed Companies, 4(3), 143-155.

Alsarayreh M.N, Jawabreh O.A, Jaradat M.F, \& Alamro S.A. (2011). Technoloical Impact on Effectiveness of Accounting Information System (AIS) Applied by Aqaba Tourist Hotels. European Journal of Scientific Research, 59(3), 361-169.

Astuti, N. M. M. P., \& Dharmadiaksa, I. B. (2014). Pengaruh Efektivitas Penerapan Sistem Informasi Akuntansi, Pemanfaatan Dan Kesesuaian Tugas Pada Kinerja Karyawan. E-Jurnal Akuntansi Universitas Udayana, 9(2), 373-384.

Awesejo, O.J, Kekwaletswe, R, M., Pretorius, P., \& Zuva, T. (2013). The Effect of Accounting Information System in Accounting. 3(1), 142-150.

Baig, A. H., \& Gururajan, R. (2011). Preliminry Study to Investigation the Determinants that Effect IS/IT Outsourcing. Journal of Information and Communication Technology Research, 1(2), 48-54.

Davis, F. . (1989). Perceived Usefulness, Perceived Ease of Use, and Acceptance of Information System Technology. Management Information Systems Quartely, 13(3), 319-339.

DeLone, W., \& McLean, E. . (1992). Information System Succes: The Qusets for 
Dependent Variable, Information System Research. 3(1), 60-95.

Dewantari, N. M. F. A., \& Putra. (2019). Pengaruh Efektivitas Penerapan SIA, Pemanfaatan TI, Kesesuaian Tugas, dan Keahlian Pemakai Komputer pada Kinerja Karyawan. E-Jurnal Akuntansi Universitas Udayana, 27, 644-674.

Dewi, N. L. A. A., \& Dharmadiaksa, I. B. (2017). Pengaruh Efektivitas Sia, Pemanfaatan TI Dan Kemampuan Teknis Pemakai Sia Terhadap Kinerja Individu. E-Jurnal Akuntansi Universitas Udayana, 18, 386-414.

Goodhue, D. ., \& Thompson, R. . (1995). Task Technology Fit and Individual Performance. In MIS Quarterly.

Hati, R. P. (2017). Pengaruh Efektivitas Penerapan Sistem Informasi Akuntansi, Pemanfaatan dan Kesesuaian Tugas Pada Kinerja Pengurus Koperasi (Aktif dan Terdaftar di Dinas Koperasi dan Usaha Mikro). Jurnal Akuntansi Universitas Riau Kepulauan.

Jackson Chintya M, Simeon Chow, \& Leitch Robert A. (1997). Toward Understanding the Behavioral Intention to Use an Information Sistem. Decision Sciences, 28(2), 357-389.

Jayantara, I. K., \& Dharmadiaksa, I. B. (2016). Pengaruh Kemampuan Teknik Pemakai Dan Efektivitas Sistem Informasi Akuntansi (Sia) Terhadap Kinerja Individual. E-Jurnal Akuntansi Universitas Udayana, 17, 2145-2170.

Jogiyanto, H. (2007). Sistem Informasi Keperilakuan. Andi.

Melasari, R. (2017). Pengaruh Sistem Informasi Akuntansi Terhadap Kinerja Karyawan Dengan Integritas Karyawan Sebagai Variabel Pemoderasi Pada Perbankan Di Tembilahan. E-Jurnal Akuntansi Dan Keuangan Universitas Islam Indragiri Tembilahan, 6(1).

Nwokeji, E. N. A. (2012). Repositioning Accounting Information System Through Effective Data Quality Management: A Framework For Reducing Cost And Improving Performance. International Journal Of Scientific \& Technology Research, 1(10).

Rahmawati, D. (2008). Analisis Faktor-Faktor yang Berpengaruh Terhadap Pemanfaatan Teknologi Informasi. Jurnal Ekonomi Dan Pendidikan, 5(1).

Sabherwal R, \& King, W. (1992). Decision Processes for Developing Strategic. Application of Information of Information sistem : A Contingency Approach. Decision Science, 23(4), 917-943.

Sarokolaei, M. A., Bishak, M. J., Rahimipoor, A., \& Sahabi, E. (2012). The Effect of Information on Efficacy of the Information of Accounting System. Journal International Conference on Economics, Trade and Development, 36(2), 174-177.

Sedarmayanti. (2009). Sumber Daya Manusia dan Produktivitas Kerja. CV Mandar Maju.

Soudani, S. N. (2012). The Usefulness of an Accounting Information System for Effective Organisational Performance. International Journal of Economics and Finance, 4(5), 136-145.

Sridarmaningr, L. G., \& Widhiyani, N. L. (2018). Pengaruh Efektivitas Sistem Informasi Akuntansi, Kesesuaian Tugas, Kenyamanan Fisik dan Lingkungan Kerja pada Kinerja Karyawan. E-Jurnal Akuntansi Universitas Udayana, 23, 1955-1979.

Urquia, E. (2011). An Effect of Accounting Information System on Performance Measure: Empirical Evidence in Spanish. Journal International of Digital 
Accounting Research, 11(2), 25-43.

Yualina, R. P., \& Suhana. (2012). Efektivitas Motivasi Kerja Dalam Meningkatkan Kinerja Pegawai. Buletin Pengelolaan Reaktor Nuklir, 9(2), 57 - 65.

Zare, I. (2012). Study of Effect of Accounting Information System and Softwares on Qualitative Features of Accounting Information. Journal of Management Science and Business Research, 1(4), 1-12. 